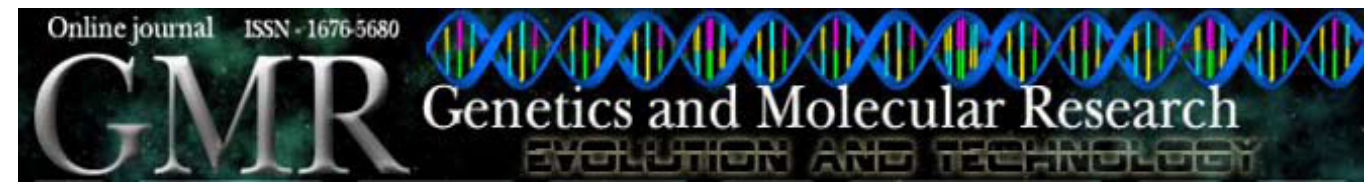

\title{
Endophytic and entomopathogenic strains of Beauveria sp to control the bovine tick Rhipicephalus (Boophilus) microplus
}

R.A. Campos ${ }^{1,2}$, J.T. Boldo ${ }^{1,4}$, I.C. Pimentel ${ }^{5}$, V. Dalfovo ${ }^{1}$, W.L. Araújo ${ }^{3}$, J.L. Azevedo ${ }^{1}$, M.H. Vainstein ${ }^{4}$ and N.M. Barros ${ }^{1}$

${ }^{1}$ Instituto de Biotecnologia, Universidade de Caxias do Sul, Caxias do Sul, RS, Brasil

${ }^{2}$ Departamento de Bioquímica, Instituto de Química, Universidade de São Paulo, São Paulo, SP, Brasil

${ }^{3}$ Núcleo Integrado de Biotecnologia, Universidade de Mogi das Cruzes, Mogi das Cruzes, SP, Brasil

${ }^{4}$ Laboratório de Biologia Molecular de Fungos Filamentosos,

Centro de Biotecnologia, Universidade Federal do Rio Grande do Sul,

Porto Alegre, RS, Brasil

${ }^{5}$ Departamento de Patologia Básica, Setor de Ciências Biológicas,

Universidade Federal do Paraná, Curitiba, PR, Brasil

Corresponding author: R.A. Campos

E-mail: betacamp2003@gmail.com

Genet. Mol. Res. 9 (3): 1421-1430 (2010)

Received April 19, 2010

Accepted May 20, 2010

Published July 20, 2010

DOI 10.4238/vol9-3gmr884

ABSTRACT. Pathogenicity of strains of the entomopathogenic fungus Beauveria bassiana and endophytic strains of Beauveria sp against the bovine tick Rhipicephalus (Boophilus) microplus was tested in laboratory bioassays and under field conditions. Suspensions containing $10^{5}, 10^{7}$ and $10^{9}$ conidia/mL were prepared of each fungal strain for laboratory bioassays. The ticks were maintained at $28^{\circ} \mathrm{C}, 90$ $\pm 5 \%$ relative humidity, and the following variables were evaluated: initial female weight, egg weight, hatching percentage, reproductive efficiency, and percentage control. For tests under field conditions, a Beauveria suspension containing $10^{6}$ conidia/mL was sprayed on tick- 
infested cows. After $72 \mathrm{~h}$, the ticks were collected to estimate mortality under field conditions. Laboratory bioassays showed a mortality of 20 to $50 \%$ of the ticks seven days after inoculation with $10^{7}$ Beauveria conidia $/ \mathrm{mL}$. Under field conditions $10^{6}$ Beauveria conidia $/ \mathrm{mL}$ induced $18-32 \%$ mortality. All Beauveria strains were effective in biological control of $R$. (Boophilus) microplus under laboratory and field test conditions. This is the first demonstration that endophytic fungi can be used for biological control of the cattle tick; this could help reduce environmental contamination by diminishing the need for chemical acaricides. Two endophytic strains were isolated from maize leaves and characterized by molecular sequencing of 5.8S rDNA ITS1 and ITS2 and morphological analyses of conidia. We found that these two endophytic Beauveria isolates, designated B95 and B157, are close to Beauveria amorpha.

Key words: Fungal acaricides; Rhipicephalus (Boophilus) microplus; Beauveria amorpha; Beauveria bassiana; Endophytic fungi

\section{INTRODUCTION}

The Asiatic bovine tick, Rhipicephalus (Boophilus) microplus (Acari, Ixodidae), is an ectoparasite that has been introduced into almost all subtropical and tropical countries through the importation of cattle. The ticks cause substantial economic losses due to reduced productivity resulting from anemia, toxicities, physical damage, and the transmission of various diseases to their hosts. Ticks are one of the largest livestock health problems in the world (Bittencourt et al., 1997; Bittencourt, 2000) and their control is mainly limited to the application of synthetic chemical products combined with management measures (Rocha, 1984). Tick control throughout the world is based mainly on the repeated use of chemical acaricides. Unlimited use of these tick-controlling chemicals has resulted in problems related to environmental pollution, milk contamination and resistance development in the target species (Onofre et al., 2001). Entomopathogenic fungi have been widely used for the control of agricultural and forest pests (Kaaya et al., 1996). The laboratory bioassay is an important test to determine the virulence of a fungal pathogen. It considers mortality and other data (egg production, egg hatchability, longevity) that could reduce the growth rate of tick populations in the field. However, comparing assay results is difficult due to variations in methods and use of different fungal isolates. Experiments under laboratory conditions (controlled temperature, humidity, day-light period) show more consistent results than do similar experiments under natural conditions, and laboratory bioassays are expected to indicate the most virulent isolates, and therefore those with greatest potential for biological control (Onofre et al., 2001; Pirali-Kheirabadi et al., 2007; Fernandes and Bittencourt, 2008). There are several groups of organisms that attack not only $R$. (B.) microplus but other Rhipicephalus species such as $R$. (B.) annulatus and $R$. (B.) decoloratus, and have potential as biocontrol agents. Among these organisms that are potential biological control agents for ticks, entomopathogenic fungi such as Beauveria bassiana, Metarhizium anisopliae and M. flavoviride appear to be satisfactory acaricides (Bittencourt et al., 1997; Monteiro et al., 1998; Pirali-Kheirabadi et al., 2007; Fernandes and 
Bittencourt, 2008; Lubeck et al., 2008; Gindin et al., 2009), being effective against ticks such as Ixodes scapularis, Oligonynchus yothersi, Rhipicephalus appendiculatus, $R$. sanguineus, Hyalomma excavatum, and Amblyomma variegatum under laboratory and field conditions (Oliveira et al., 2002; Leemon et al., 2008). The entomopathogenic B. bassiana is usually found infecting insects. However, members of the genus Beauveria have also been isolated from plants, and thus considered to be endophyte strains (Bing and Lewis 1991; Wagner and Lewis 2000), which probably protect the host plant against the attack by insects. Strains of Beauveria are able to produce several cuticle-degrading hydrolytic extracellular enzymes such as chitinases and $\beta-1,3$-glucanases, all of which are considered to be determinants of fungal pathogenicity (Gupta et al., 1992; St. Leger et al., 1993). Hyphal modifications (appressorium) are also important as physical structures that help Beauveria strains to penetrate the cuticle of its hosts (Mendgen et al., 1996; Bastmeyer et al., 2002; Campos et al., 2005). B. bassiana and $M$. anisopliae secrete toxic metabolites during the infection process that contribute to the establishment and progression of disease (Alves, 1998). Also, B. bassiana and B. amorpha produce subtilisin-like proteases and chitinases in the presence of $R$. (B.) microplus tick cuticle (Campos et al., 2005). The use of chemical acaricides for tick control has resulted in problems related to environmental pollution, milk contamination and development of resistance in the target species. Since biological control is an attractive alternative method for controlling ticks, we evaluated the potential of two new endophytic and two entomopathogenic Beauveria strains as biological control agents for $R$. (B.) microplus.

\section{MATERIAL AND METHODS}

\section{Fungal strains}

Two entomopathogenic Beauveria bassiana (Bals.-Criv) Vuillemin (Ascomycetes, Hypocreales) strains, CG166, isolated from Schrius sp (Lepidoptera: Saturnidae), and CG478, isolated from Anthonomus grandis (Coleoptera: Curculionidae) were supplied by CENARGEN Laboratories, EMBRAPA, Brasília, Brazil. Two endophytic Beauveria strain isolates from leaves of maize, Zea mays, designated B95 and B157, were also used.

\section{Isolation of endophytic fungi}

Hybrid maize (Zea mays L. OC 705) was grown in the field and in a greenhouse in the Canguiri Experimental Station at the Federal University of Paraná, Brazil, using non-fertilized soil free from insecticides and other chemicals. Only plants exhibiting healthy vegetative growth were used. Leaves and stems were collected from field-grown and greenhouse-grown plants 3 weeks after emergence and at the end of the reproductive phase, about 7 weeks after seed germination. The plant samples were washed twice in sterile water, surface-disinfected by immersion in $70 \%$ ethanol for 1 min followed by 3\% sodium hypochlorite for 4 min and $70 \%$ ethanol for $30 \mathrm{~s}$, and rinsed three times with sterile water. After surface disinfection, leaves and stems were peeled and cut into 10 fragments $(5-7 \mathrm{~mm})$, which were placed on potato dextrose agar (PDA) culture medium supplied with $100 \mu \mathrm{g} / \mathrm{mL}$ tetracycline. The plates were incubated at $28^{\circ} \mathrm{C}$ and checked every day for 30 days. The number of fragments showing fungal growth was determined and recorded. The hyphal tip of each morphologically different 
mycelium that emerged from a branch fragment was transferred to PDA slants for later identification (Pimentel, 2001). Following incubation, fungal isolates recovered from each plant fragment were selected at random, purified and grouped on the basis of phenotypic characteristics such as colony morphology, color and growth rate. Isolates representing each fungal group of interest were selected for further identification by morphological characteristics and rDNA sequencing.

\section{DNA extraction and rDNA sequencing of endophytic Beauveria strains}

The DNA of Beauveria isolates was extracted according to Raeder and Broda (1985) and further characterized by sequencing 5.8S rDNA, internal transcribed spacers 1 and 2 (ITS-1 and ITS2), using the primers ITS1F (5'-TCCGTAGGTGAACCTGCGG-3') and ITS4 (5'-TCCTCCGCTTATTGATATGC-3'), which are universal primers for the fungal group. Polymerase chain reaction (PCR) was carried out in a $50-\mathrm{mL}$ final volume containing $2 \mathrm{~mL}$ template DNA (5-10 ng), $0.4 \mathrm{mM}$ of each primer, $200 \mathrm{mM}$ of each dNTP, $3.7 \mathrm{mM} \mathrm{MgCl}_{2}$ and

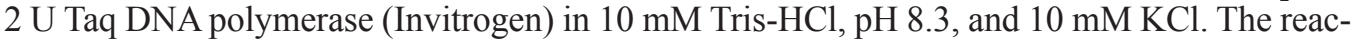
tion conditions were as follows: $94^{\circ} \mathrm{C}$ for $1 \mathrm{~min}$ for initial denaturation and 30 cycles of $30 \mathrm{~s}$ at $94^{\circ} \mathrm{C}, 30 \mathrm{~s}$ at $55^{\circ} \mathrm{C}$ and $30 \mathrm{~s}$ at $72^{\circ} \mathrm{C}$, followed by a final extension at $72^{\circ} \mathrm{C}$ for $7 \mathrm{~min}$. A negative control was included in all PCR experiments. The purified PCR products (GFX PCR DNA Kit, GE Healthcare Life Science) were sequenced using ITS-1 and ITS-4 primers and the sequences compared to the GenBank database using the BLASTn program (Altschul et al., 1990).

\section{Nucleotide sequence analysis and accession numbers}

The rDNA sequence alignment was performed using ClustalX (Thompson et al., 1999). The phylogenetic analyses were performed with the Geneious Program Tree Builder Release 4.6.4, neighbor-joining method (Saitou and Nei, 1987), and Jukes-Cantor correct distance model (Jukes and Cantor, 1969). The nucleotide sequences obtained in this study were submitted to GenBank, accession numbers $\underline{\text { AY388629 }}$ and AY388630.

\section{Ticks}

Males and females of $R$. (B.) microplus were collected, according to the method described in Bittencourt et al. (1997), from naturally infested adult Holstein-Friesian cows pastured at 3 dairy farms (coded A, B and C) located close to the town of Serafina Correia (S28 42'42"/W51 '56'06") in Rio Grande do Sul State, southern Brazil. The ticks were transported to the laboratory, washed in a $0.25 \%(\mathrm{v} / \mathrm{v})$ sodium hypochlorite solution, rinsed with $0.85 \% \mathrm{NaCl}(\mathrm{w} / \mathrm{v})$ twice and dried. Females were selected and weighed to obtain the initial female weight (IFW), and homogenous weight groups were placed on Petri dishes.

\section{Fungal growth and preparation of conidial suspensions}

Stock cultures of the fungal strains were maintained on Sabouraud dextrose agar (SDA). To prepare conidial suspensions, the individual stock cultures were transferred to Petri dishes containing SDA and incubated for 15 days at $28^{\circ} \mathrm{C}$, after which conidia from the 
grown colonies were transferred to test tubes containing $10 \mathrm{~mL}$ aqueous $0.1 \%(\mathrm{v} / \mathrm{v})$ Tween 80 . The number of conidia was estimated using a Neubauer hemocytometer. For the bioassays, the conidial suspensions were decimally diluted to produce pure-strain suspensions containing $10^{5}$, $10^{7}$, and $10^{9}$ conidia $/ \mathrm{mL}$. For the field tests, $25 \mathrm{~mL}$ of a single-strain suspension containing about $10^{6}$ conidia/mL was prepared in aqueous $0.1 \%(\mathrm{v} / \mathrm{v})$ Tween 80 , added to $250 \mathrm{~g}$ sterilized rice in conical flasks and incubated for 15 days at $28^{\circ} \mathrm{C}, 60-80 \%$ relative humidity and a $16: 8$-h photoperiod. After incubation, cultures were pooled in a $25-\mathrm{L}$ receptacle with $20 \mathrm{~L}$ aqueous $0.1 \%(\mathrm{v} / \mathrm{v})$ Tween 80 and $0.05 \%$ (w/v) Mineral Adhesive Attach (Novartis). The receptacles were shaken to form a conidial suspension, which was decanted from rice and transferred to clean receptacles. This procedure was repeated several times to produce the amount of conidial suspension necessary for the tests under field conditions. For both laboratory bioassays and field tests, the procedures above were repeated for each strain.

\section{Laboratory bioassays}

Beauveria strain suspensions $\left(10^{5}, 10^{7}\right.$ and $10^{9}$ conidia $\left./ \mathrm{mL}\right)$ were bioassayed (in triplicate) for $R$. (B.) microplus pathogenicity by immersing 10 engorged females (360 in total) in each of the suspensions for $1 \mathrm{~min}$ and then transferring the specimens to sterile Petri dishes containing moist filter paper, where they were kept for up to 20 days at $28^{\circ} \mathrm{C}$ and $90 \pm 5 \%$ relative humidity. Three control groups of 10 engorged $R$. (B.) microplus females (30 in total) were treated in the same way, except that they were immersed in sterile aqueous $0.1 \%(\mathrm{v} / \mathrm{v})$ Tween 80 solution instead of conidial suspension. Both Beauveria-treated and control ticks were evaluated for infection and mortality every $24 \mathrm{~h}$. The Stendel (1980) method was used to obtain the IFW in grams of each tick before immersion in the conidial suspensions. Egg weight (EW) was obtained by separating the eggs from the females and weighing the eggs, which were then placed in test tubes and the hatching percentage $(\mathrm{H} \%)$ was visually determined. Reproductive efficiency (RE) was calculated as RE $=\mathrm{EW} / \mathrm{IFW} \times \mathrm{H} \%$, and the reproductive efficiency of the Beauveria-treated group was evaluated. Mortality percentage (M\%), represented by the number of dead female ticks, was calculated as $M \%=R E_{c}-R E_{t} / R E_{c} x$ $100(t=$ treated group; $\mathrm{c}=$ control group) (Stendel, 1980). Data were subjected to analysis of variance (ANOVA) and means compared using the Duncan test $(\mathrm{P}<0.05)$. Median lethal dose $\left(\mathrm{LD}_{50}\right)$ values were calculated using the probit analysis (Finney, 1971).

\section{Tests under field conditions}

The test under field conditions was carried out in southern Brazil between September and February of 2006 and 2009, the spring-summer seasons in Brazil, where the incidence of parasites on cattle is higher. Holstein-Friesian cows infested with $R$. (B.) microplus, from the same three dairy farms (A, B and C) used before for tick-collection for the laboratory bioassays, were used for field tests. The group of cows used for each fungal strain and an additional group were used as the control, which was sprayed with the same volume of aqueous $0.1 \%(\mathrm{v} / \mathrm{v})$ Tween- 80 . The treated groups were sprayed with $3 \mathrm{~L}$ Beauveria suspension containing $10^{6}$ conidia/mL and then stabled for $72 \mathrm{~h}$ after which all ticks were collected both from cows and the adjacent stable floor. Dead ticks were counted and washed for $1 \mathrm{~min}$ in a $0.25 \%(\mathrm{v} / \mathrm{v})$ sodium hypochlorite solution and placed on SDA plates, which were incubated at $28^{\circ} \mathrm{C}$ for up to 15 days to determine the presence of Beauveria. 


\section{RESULTS AND DISCUSSION}

Our aim was the characterization and identification of two new endophytic Beauveria isolates designated $\mathrm{B} 95$ and $\mathrm{B} 157$. These isolates and two entomopathogenic fungi of $B$. bassiana were evaluated for biological control of $R$. (B.) microplus by laboratory bioassay and under field conditions. The results show that the Beauveria strains tested in the laboratory bioassays reduced EW and significantly reduced RE, where in both cases, the EW and RE values decreased progressively with increase in the concentration of conidia used (Table 1). The mortality showed that endophytic Beauveria strains (B95 and B157) and the entomopathogenic strain CG478 were equally efficient at killing $R$. (B.) microplus females (Figure 1). The $\mathrm{LD}_{50}$ values differed for each Beauveria strain tested (Table 2).

\begin{tabular}{|c|c|c|c|c|c|}
\hline Fungal strain & Conidia $/ \mathrm{mL}$ & Initial female weight $(\mathrm{g})$ & Egg weight (g) & Reproductive efficiency & Mortality percentage \\
\hline \multirow[t]{3}{*}{ B95 } & $10^{9}$ & $2.11 \pm 0.08$ & $0.56 \pm 0.01$ & $10.31 \pm 0.25^{\mathrm{a}}$ & $86.54 \pm 0.34^{\mathrm{a}}$ \\
\hline & $10^{7}$ & $2.07 \pm 0.06$ & $0.65 \pm 0.01$ & $14.80 \pm 0.36^{\mathrm{bc}}$ & $80.28 \pm 0.48^{\mathrm{bc}}$ \\
\hline & $10^{5}$ & $2.04 \pm 0.03$ & $0.83 \pm 0.01$ & $27.66 \pm 0.40^{\mathrm{d}}$ & $66.42 \pm 2.59^{d}$ \\
\hline \multirow[t]{3}{*}{ B157 } & $10^{9}$ & $2.08 \pm 0.04$ & $0.57 \pm 0.03$ & $13.19 \pm 0.98^{\mathrm{ab}}$ & $82.77 \pm 1.29^{\mathrm{ab}}$ \\
\hline & $10^{7}$ & $2.05 \pm 0.05$ & $0.69 \pm 0.02$ & $18.36 \pm 1.44^{\mathrm{c}}$ & $75.55 \pm 1.91^{\mathrm{c}}$ \\
\hline & $10^{5}$ & $2.04 \pm 0.05$ & $0.85 \pm 0.03$ & $30.17 \pm 0.99^{\mathrm{de}}$ & $61.83 \pm 1.25^{\mathrm{e}}$ \\
\hline \multirow[t]{3}{*}{ CG166 } & $10^{9}$ & $2.05 \pm 0.06$ & $0.63 \pm 0.05$ & $13.56 \pm 1.30^{\mathrm{b}}$ & $82.29 \pm 1.69^{b}$ \\
\hline & $10^{7}$ & $2.19 \pm 0.03$ & $0.85 \pm 0.03$ & $20.14 \pm 1.07^{c}$ & $73.17 \pm 1.43^{\mathrm{c}}$ \\
\hline & $10^{5}$ & $2.13 \pm 0.06$ & $0.88 \pm 0.02$ & $32.65 \pm 0.46^{\mathrm{e}}$ & $58.70 \pm 0.58^{\mathrm{e}}$ \\
\hline \multirow[t]{3}{*}{ CG478 } & $10^{9}$ & $2.13 \pm 0.11$ & $0.67 \pm 0.05$ & $12.69 \pm 0.97^{\mathrm{ab}}$ & $83.42 \pm 1.23^{\mathrm{ab}}$ \\
\hline & $10^{7}$ & $2.15 \pm 0.12$ & $0.82 \pm 0.06$ & $17.79 \pm 0.92^{\mathrm{bc}}$ & $76.31 \pm 1.22^{\mathrm{bc}}$ \\
\hline & $10^{5}$ & $2.07 \pm 0.07$ & $0.95 \pm 0.03$ & $30.49 \pm 0.51^{\mathrm{de}}$ & $61.44 \pm 0.64^{\mathrm{e}}$ \\
\hline Control & 0 & $2.07 \pm 0.04$ & $1.70 \pm 0.02$ & $76.94 \pm 2.00^{\mathrm{f}}$ & 0 \\
\hline
\end{tabular}

Different superscript letters in the same column indicate a significant difference between concentrations by the Duncan test $(\mathrm{P}<0.05)$.

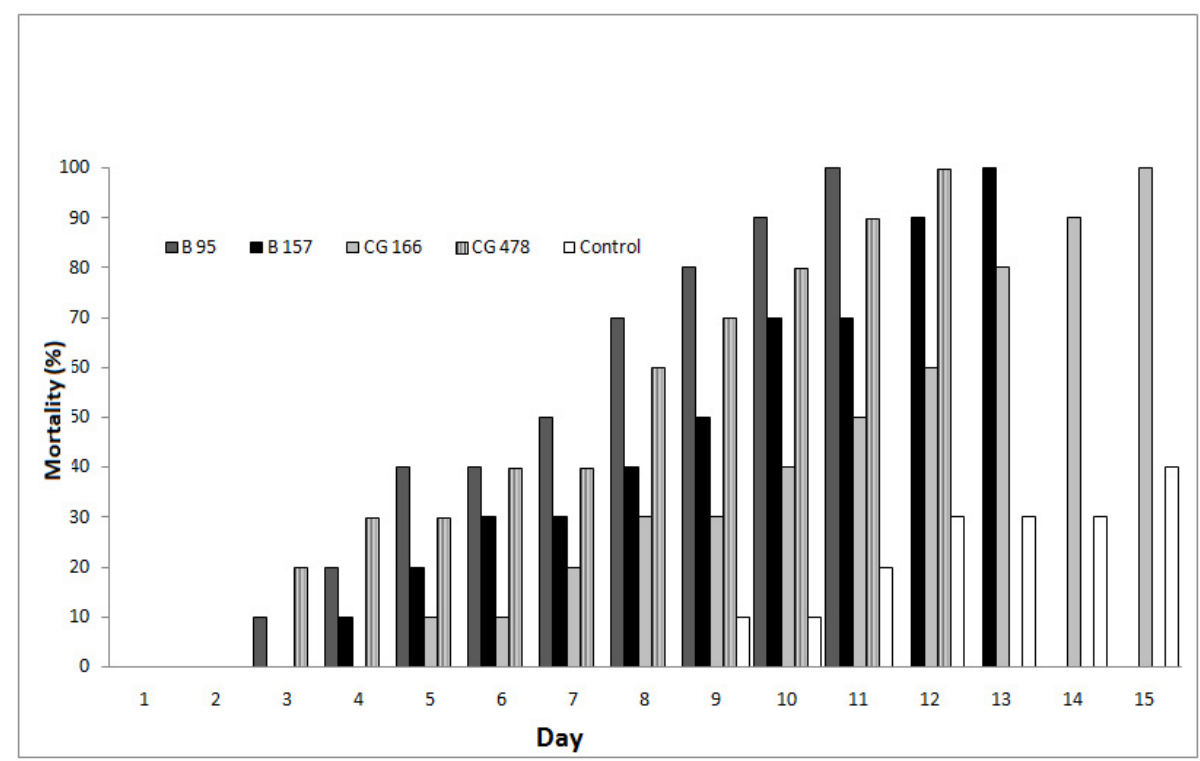

Figure 1. Rhipicephalus (Boophilus) microplus female mortality caused by different fungal strains of Beauveria. 


Table 2. Lethal dose $\left(\mathrm{LD}_{50}\right)$ for engorged Rhipicephalus (Boophilus) microplus females.
\begin{tabular}{lccc}
\hline Beauveria strain & $\mathrm{LD}_{50}($ conidia/mL) & $95 \%$ confidence limits & Probit x-axis* \\
\hline B95 & $5.4 \times 10^{5}$ & $1.9 \times 10^{5}-3.5 \times 10^{6}$ & $-2.23+0.405\left[\log 10\left\{\right.\right.$ dose $\left.\left._{\mathrm{i}}\right\}\right]$ \\
B157 & $7.6 \times 10^{8}$ & $3.5 \times 10^{8}-1.3 \times 10^{9}$ & $-2.21+0.34\left[\log 10\left\{\right.\right.$ dose $\left.\left.^{\mathrm{i}}\right\}\right]$ \\
CG166 & $4.6 \times 10^{9}$ & $2.3 \times 10^{9}-8.6 \times 10^{9}$ & $-2.47+0.24\left[\log 10\left\{\operatorname{dose}_{\mathrm{i}}\right\}\right]$ \\
CG478 & $2.3 \times 10^{7}$ & $8.6 \times 10^{6}-5.7 \times 10^{7}$ & $-2.45+0.31\left[\log 10\left\{\right.\right.$ dose $\left.\left._{\mathrm{i}}\right\}\right]$ \\
\hline
\end{tabular}

*All values were calculated using the probit analysis (Finney, 1971).

The field tests showed that the mortality of $R$. (B.) microplus varied from 18.6 to $32.4 \%$. The endophytic Beauveria strain B95 was the most efficient, followed by the entomopathogenic strain CG478 (Table 2). The endophytic Beauveria strain B95 induced the highest mortality percentage, and the entomopathogenic $B$. bassiana strain CG166 produced the lowest $R$. (B.) microplus mortality percentage (Figure 1). It has been reported that $B$. bassiana is an effective biological control agent for several Rhipicephalus species, including $R$. (B.) microplus and $R$. (B.) annulatus, with $R$. (B.) annulatus showing an in vitro mortality around $45 \% 7$ days after treatment with B. bassiana (Bittencourt et al., 1997; Paião et al., 2001). Species of the fungus Metarhizium have also been used to control R. (B.) microplus based on similar procedures and variables (Onofre et al., 2001) as those used in bioassays previously reported. Our results using Beauveria strains are comparable to those obtained with $M$. anisopliae (Onofre et al., 2001) indicating that, in laboratory bioassays, Beauveria and Metarhizium are equally effective in controlling $R$. (B.) microplus, with the $\mathrm{LD}_{50}$ values for the Beauveria strains (Table 1) being similar to those recorded for Metarhizium strains. Endophytic fungi are commonly found inhabiting grasses (Graminae) (Azevedo et al., 2000) and Beauveria is also found in the soil (Hughes et al., 2004). The strains used in the present study were isolated from maize, and it is likely that they may also be encountered in association with pasture grasses, where they may act as a natural tick control agent. In fact, a combination of plant extracts and pasture grasses able to control ticks (Kaaya, 2000) may be a way to develop some form of integrated control (Kaaya, 1994). To our knowledge, endophytic fungi have not been previously evaluated for their pathogenicity against ticks. The results of the field tests showed that the mean mortality caused by strains B95, CG478 and B157 was superior to that produced by strain GC166 (Table 2). These are the first tests under field conditions in Brazil using endophytic fungi for the control of $R$. (B.) microplus. Field tests using B. bassiana and M. anisopliae for the biological control of the African tick $R$. (B.) appendiculatus resulted in $41 \%$ tick mortality 6 days after treatment, and some reports have indicated that mortality can be as high as 76-85\% (Mwangi et al., 1995; Kaaya et al., 1996; Kaaya, 2000).

Fungal isolates capable of inducing such high mortalities at all stages in the life cycle of ticks are likely to significantly reduce tick populations and, consequently, the incidence of tick-borne and tick-associated diseases. Several sequences of Beauveria species from the GenBank database were compared with sequences of two endophytic Beauveria isolates, B95 and B157. Phylogenetic analysis showed that the isolates are closer to Beauveria amorpha (Höhn.) than B. bassiana (Figure 2). Optical and scanning microscopy assays using isolates B95 and B157 to measure conidial size and shape were performed to verify the Beauveria endophytic isolates (Sia, 2006): in particular, B157 conidia are much larger than B. bassiana conidia, showing a flattened shape. 


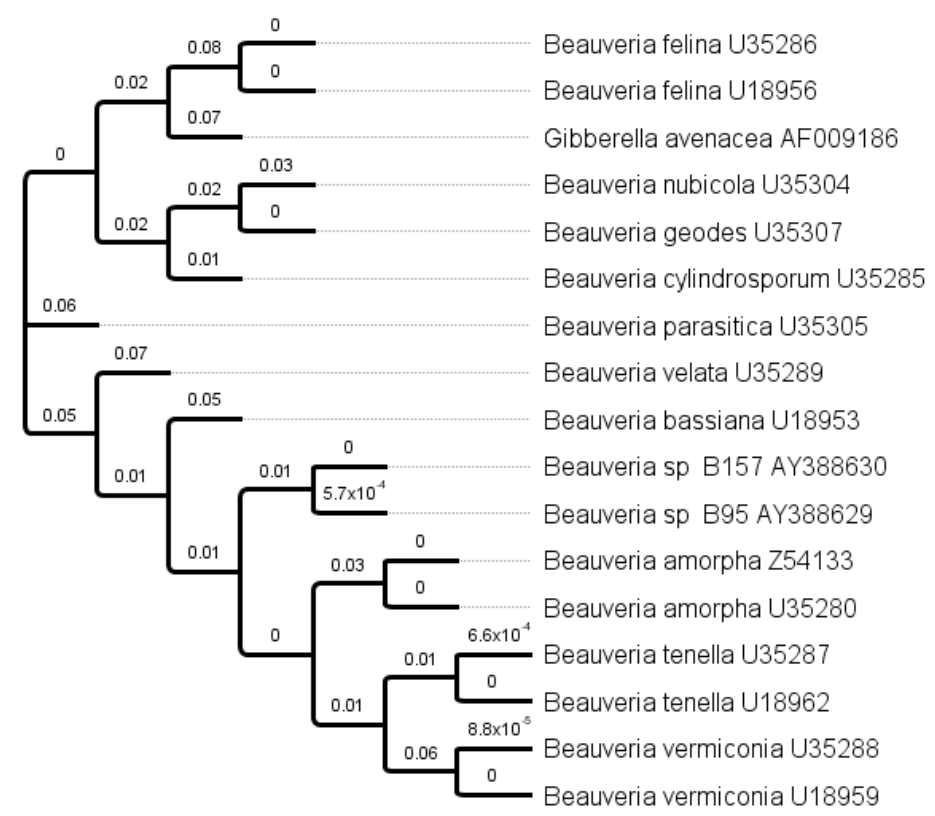

Figure 2. Phylogenetic analysis of two endophytic isolates belonging to the Beauveria genus. Neighbor-joining method. Numbers on the tree branches indicate the Jukes-Cantor distance. Geneious Program Tree Builder, Release 4.6.4. Entophytic strains available in GenBank accession Nos. AY388629 and AY388630.

These results are in agreement with results described by Campos et al. (2005), where scanning electron microscopy was used in order to find morphologic differences between the Beauveria species studied and their form of penetration of the cattle tick cuticle. The conidial morphology of $B$. bassiana showed a spherical shape, whereas $B$. amorpha conidia on ticks were often flattened on the side as in the original descriptions by Glare and Inwood (1998), indicating that isolates B95 and B157 are closer to B. amorpha. The use of Beauveria in a biological control program in Brazil and other countries could reduce the use of chemical acaricides and could result not only in lower costs to the farmer but also in a lower environmental impact and less damage to nature.

\section{REFERENCES}

Altschul SF, Gish W, Miller W, Myers EW, et al. (1990). Basic local alignment search tool. J. Mol. Biol. 215: 403-410. Alves SB (1998). Fungos Entomopatogênicos. In: Controle Microbiano de Insetos (Alves SB, ed.). 2nd edn. Editora Fealq, Piracicaba, 289-381.

Azevedo JL, Maccheroni W Jr, Pereira JO and Araújo WL (2000). Endophytic microorganisms: a review on insect control and recent advances on tropical plants. Electron. J. Biotechnol. 3: 40-65.

Bastmeyer M, Deising HB and Bechinger C (2002). Force exertion in fungal infection. Annu. Rev. Biophys. Biomol. Struct. 31: 321-341.

Bing LA and Lewis LC (1991). Suppression of the European corn borer, Ostrinia nubilalis (Hbn.) (Lepidoptera: Pyralidae) by endophytic Beauveria bassiana (Bals.) Vuill. Environ. Entomol. 20: 1207-1211.

Bittencourt VREP (2000). Controle Biológico de Carrapatos. In: Controle Biológico (Melo IS and Azevedo JL, eds.). Vol. 2. EMBRAPA, Jaguariúna, 145-171.

Bittencourt VREP, Souza EJ, Peralva SLFS, Mascarenhas AG, et al. (1997). In vitro efficacy evaluation of two isolates 
of the fungi Beauveria bassiana (Bals.) Vuill. in Boophilus microplus (Canestrini, 1887) (Acari: Ixodidae) engorged females. Rev. Bras. Parasitol. Vet. 6: 49-52.

Campos RA, Arruda W, Boldo JT, da Silva MV, et al. (2005). Boophilus microplus infection by Beauveria amorpha and Beauveria bassiana: SEM analysis and regulation of subtilisin-like proteases and chitinases. Curr. Microbiol. 50: 257-261.

Fernandes EK and Bittencourt VR (2008). Entomopathogenic fungi against South American tick species. Exp. Appl. Acarol. 46: 71-93.

Finney DJ (1971). Probit Analysis. Cambridge University Press, Cambridge.

Gindin G, Ment D, Rot A, Glazer I, et al. (2009). Pathogenicity of Metarhizium anisopliae (Hypocreales: Clavicipitaceae) to tick eggs and the effect of egg cuticular lipids on conidia development. J. Med. Entomol. 46: 531-538.

Glare TR and Inwood AJ (1998). Morphological and genetic characterisation of Beauveria spp. from New Zealand. Mycol. Res. 102: 250-256.

Gupta SC, Leathers TD, El-Sayed GN and Ignoffo CM (1992). Insect cuticle-degrading enzymes from the entomogenous fungus Beauveria bassiana. Exp. Mycol. 16: 132-137.

Hughes WO, Thomsen L, Eilenberg J and Boomsma JJ (2004). Diversity of entomopathogenic fungi near leaf-cutting ant nests in a Neotropical forest, with particular reference to Metarhizium anisopliae var. anisopliae. J. Invertebr. Pathol. 85: 46-53.

Jukes TH and Cantor CR (1969). Evolution of Protein Molecules. In: Mammalian Protein Metabolism (Munro HN, ed.). Academic Press, New York, 21-132.

Kaaya GP (1994). Achieving sustainable food production in Africa: roles of pesticides and biological control in integrated pest management. Insect Sci. Appl. 15: 223-234.

Kaaya GP (2000). Laboratory and field evaluation of entomogenous fungi for tick control. Ann. N. Y. Acad. Sci. 916: 559-564.

Kaaya GP, Mwangi EN and Ouna EA (1996). Prospects for biological control of livestock ticks, Rhipicephalus appendiculatus and Amblyomma variegatum, using the entomogenous fungi Beauveria bassiana and Metarhizium anisopliae. J. Invertebr. Pathol. 67: 15-20.

Leemon DM, Turner LB and Jonsson NN (2008). Pen studies on the control of cattle tick (Rhipicephalus (Boophilus) microplus) with Metarhizium anisopliae (Sorokin). Vet. Parasitol. 156: 248-260.

Lubeck I, Arruda W, Souza BK, Stanisçuaski F, et al. (2008). Evaluation of Metarhizium anisopliae strains as potential biocontrol agents of the tick Rhipicephalus (Boophilus) microplus and the cotton stainer Dysdercus peruvianus. Fungal Ecol. 1: 78-88.

Mendgen K, Hahn M and Deising H (1996). Morphogenesis and mechanisms of penetration by plant pathogenic fungi. Annu. Rev. Phytopathol. 34: 367-386.

Monteiro AC, Fiorin AC and Correia ACB (1998). Pathogenicity of isolates of Metarhizium anisopliae (Metsch.) Sorokin towards the cattle tick Boophilus microplus (Can.) (Acari: Ixodidae) under laboratory conditions. Rev. Microbiol. 29: 109-112.

Mwangi EN, Kaaya GP and Essuman S (1995). Experimental infections of the tick Ripicephalus appendiculatus with pathogenic fungi, Beauveria bassiana and Metarhizium anisopliae, and natural infections of some ticks with bacteria and fungi. J. Afr. Zool. 109: 151-160.

Oliveira RC, Alves LFA and Neves PMOJ (2002). Susceptibility of Oligonychus yothersi (Acari: Tetranychidae) to the fungus Beauveria bassiana. Sci. Agric. 59: 187-189.

Onofre SB, Miniuk CM, de Barros NM and Azevedo JL (2001). Pathogenicity of four strains of entomopathogenic fungi against the bovine tick Boophilus microplus. Am. J.Vet. Res. 62: 1478-1480.

Paião JCV, Monteiro AC and Kronka SN (2001). Susceptibility of the cattle tick Boophilus microplus (Acari: Ixodidae) to isolates of the fungus Beauveria bassiana. World J. Microbiol. Biotechnol. 17: 245-251.

Pimentel IC (2001). Fungos Endofíticos de Milho (Zea mays L.) e Soja (Glycine max L. Merril) e seu Potencial Biotecnológico no Controle de Pragas Agrícolas. Doctoral thesis, Universidade Federal do Paraná, Curitiba.

Pirali-Kheirabadi K, Haddadzadeh H, Razzaghi-Abyaneh M, Bokaie S, et al. (2007). Biological control of Rhipicephalus (Boophilus) annulatus by different strains of Metarhizium anisopliae, Beauveria bassiana and Lecanicillium psalliotae fungi. Parasitol. Res. 100: 1297-1302.

Raeder U and Broda P (1985). Rapid preparation of DNA from filamentous fungi. Lett. Appl. Microbiol. 1: 17-20.

Rocha UR (1984). Biologia e controle biológico do carrapato Boophilus microplus (Canestrini). Bol. Tec. Fac. Cienc. Agric. Vet. Jaboticabal 3: 1-32.

Saitou N and Nei M (1987). The neighbor-joining method: a new method for reconstructing phylogenetic trees. Mol. Biol. Evol. 4: 406-425.

Sia EF (2006). Isolados Endofíticos e Entomopatogênicos de Beauveria: Caracterização e Importância Biotecnológica. Masther thesis, Universidade de Mogi das Cruzes, Mogi das Cruzes.

St. Leger RJ, Staples RC and Roberts DW (1993). Entomopathogenic isolates of Metarhizium anisopliae, Beauveria

Genetics and Molecular Research 9 (3): 1421-1430 (2010)

CFUNPEC-RP www.funpecrp.com.br 
bassiana, and Aspergillus flavus produce multiple extracellular chitinase isozymes. J. Invert. Pathol. 61: 81-84.

Stendel W (1980). The relevance of different test methods for the evaluation of tick controlling substances. J. S. Afr. Vet. Assoc. 51: 147-152.

Thompson JD, Plewniak F and Poch O (1999). A comprehensive comparison of multiple sequence alignment programs. Nucleic Acids Res. 27: 2682-2690.

Wagner BL and Lewis LC (2000). Colonization of corn, Zea mays, by the entomopathogenic fungus Beauveria bassiana. Appl. Environ. Microbiol. 66: 3468-3473. 